\title{
Software para Auxílio no Processo de Elaboração do Cariótipo
}

\author{
Guilherme Chagas Kurtz ${ }^{1}$ \\ Gustavo Stangherlin Cantarelli ${ }^{1}$ \\ Michele Rorato Sagrillo ${ }^{1}$ \\ Fernando Gomes Pires ${ }^{1}$ \\ Data de submissão: 24.02 .2015 \\ Data de aceitação: 05.06.2015
}

Resumo: Muitas anomalias e doenças genéticas podem ser descobertas através da análise da forma e das características morfológicas dos cromossomos. Para alcançar este objetivo, geralmente constrói-se o cariótipo, a partir de uma fotografia obtida através de um microscópio, através da organização e ordenação dos cromossomos de uma célula humana de acordo com o seu tamanho. Apesar dos grandes avanços nas técnicas de cultura celular, bandeamento, coleta e análise dos materiais para a elaboração do cariótipo, este processo ainda é bastante empregado de forma manual, pois a oferta de sistemas automáticos que auxiliem o trabalho dos geneticistas ainda é baixa. Através da automatização deste processo é possível agilizar condutas terapêuticas, obtendo resultados em um espaço de tempo menor. Desta forma, este trabalho propõe o desenvolvimento de uma ferramenta capaz de auxiliar o geneticista na elaboração do cariótipo humano através da automatização do processo de segmentação de metáfases e identificação dos cromossomos através de imagens obtidas de um microscópio.

\footnotetext{
${ }^{1}$ Centro Universitário Franciscano, Santa Maria, RS, Brasil.

\{guilhermekurtz, gus.cant, sagrillomr @unifra.br\}

\{fernandogomespires@hotmail.com \}
} 
Abstract: Many anomalies and genetic diseases can be discovered by analyzing the shape and morphological characteristics of the chromosomes. To accomplish this, usually the karyotype is built, from a photograph obtained through a microscope, through the organization and ordering of chromosomes in a human cell according to its size. Despite major advances in cell culture techniques, banding, collection and analysis of materials for the preparation of the karyotype, this process is still done manually, because the supply of automated systems that assist the work of geneticists is still low. By automating this process is possible to speed up therapeutic conducts, getting results in a shorter span of time. Thus, this paper proposes the development of a tool to assist the geneticist in the preparation of human karyotype by automating the segmentation of metaphases and identification of chromosomes process through images taken by a microscope. 


\section{Introdução}

Nas últimas duas décadas, a área da Genética, em especial a Genética Médica, cresceu muito no Brasil e tem atraído um grande número de profissionais. A Citogenética humana foi uma de suas primeiras subáreas a serem implantadas no país, inicialmente em laboratórios de pesquisa e, mais recentemente, também em laboratórios de análises clínicas. Atualmente, suas aplicações incluem a caracterização de polimorfismos nas populações e a pesquisa da ação de agentes mutagênicos (que causam mutações ou mudanças na forma do DNA) ou carcinogênicos (que causam mutações e levam a ativação de genes tumorais) em ensaios in vitro, além da análise de cariótipo em muitas doenças. Suas técnicas compreendem importantes ferramentas de diagnóstico pré e pós-natal de anomalias congênitas (alterações nas quais os indivíduos já nascem com ela) e de diagnóstico e monitoramento de terapia em casos de neoplasias, principalmente hematológicas [1][16].

Os avanços ocorridos nas técnicas de cultura celular, bandeamento, coleta e análise dos materiais para a execução do cariótipo possibilitaram grandes progressos no diagnóstico das alterações cromossômicas, mas apesar da demanda crescente deste tipo de exame, é pequena a oferta de sistemas automáticos que auxiliem o trabalho dos geneticistas na geração do cariótipo [1][3]. A possibilidade de se obter resultado em curto espaço de tempo, agilizando condutas terapêuticas ou tranquilizando a família, tem um valor inestimável. Assim, o cariótipo no diagnóstico clínico é uma verdadeira corrida contra o tempo [2][17].

Portanto, o desenvolvimento de um sistema computadorizado utilizando técnicas de visão por computador pode servir de auxílio ao geneticista tanto na otimização do trabalho quanto na execução da análise da forma dos cromossomos humanos. Através da automatização do processo de identificação dos cromossomos e elaboração do cariótipo, é possível aumentar a homogeneidade dos resultados da análise dos cromossomos permitindo sua análise detalhada, onde a impressão das imagens digitalizadas dos cariótipos poderá ser enviada juntamente com os resultados. A meta dos laboratórios que prestam serviços nessa área deve ser o desenvolvimento de uma política de qualidade que faça com que o número de erros tenda a zero e que os laudos emitidos sejam compreensíveis pelos profissionais que atuam junto ao paciente.

Desta forma, o objetivo deste trabalho é o desenvolvimento de uma ferramenta capaz de auxiliar o geneticista na tarefa de elaboração do cariótipo humano através da automatização do processo de segmentação de metáfases e identificação de cromossomos, a partir de imagens obtidas através de um microscópio.

Este artigo está organizado da seguinte forma: a Seção 2 apresenta uma breve revisão bibliográfica a respeito do processo de elaboração do cariótipo. A Seção 3 apresenta metodologia utilizada para o desenvolvimento da ferramenta, e a Seção 4 irá mostrar detalhes da ferramenta propriamente dita, bem como resultados obtidos. Por fim, na Seção 5, a conclusão deste trabalho. 


\section{Processo de Elaboração do Cariótipo}

O processo de análise e identificação de cromossomos é chamado cariotipagem. A Figura 1.a traz um exemplo de uma metáfase de uma célula humana (conjunto de cromossomos em uma célula), e a Figura 1.b um exemplo de metáfase já identificada, em que o processo de identificação dos cromossomos já foi feito (cariotipagem). Esse processo é geralmente utilizado como recurso para investigação de alterações cromossômicas que podem ser responsáveis por diversos problemas de saúde.

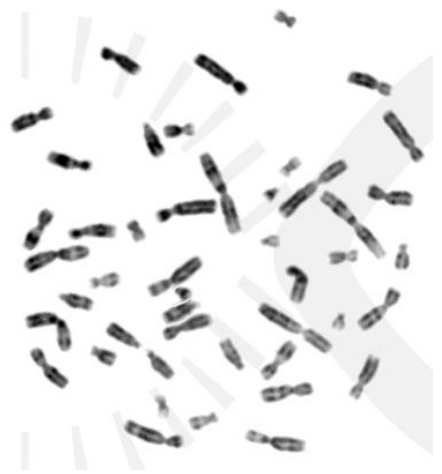

(a)

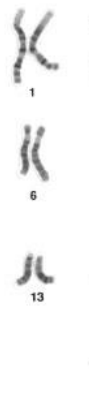

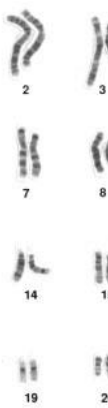

(b)

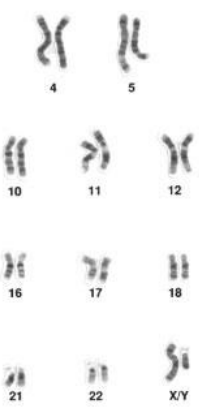

Figura 1 - Metáfase (a) e Cariótipo (b) de celulas humanas [7].

Dessas alterações, podemos citar neoplasias (cânceres), síndromes genéticas, quebras cromossômicas (causadas por radiação, por exemplo). Além disso, é possível dar um prognóstico ao paciente, ou seja, definir a evolução de uma doença em certo organismo (nesse caso, em humanos) e a seguir descrever-lhe a conduta terapêutica necessária [3].

Geralmente, este processo de análise e identificação dos cromossomos é feito de forma manual por um geneticista, sendo que este processo podedurar em torno de meia hora para cada imagem. O processo de identificação manual envolve as seguintes etapas:

1. Aquisição da imagem - geralmente através de uma câmera acoplada a um microscópio;

2. Segmentação e identificação dos cromossomos - processo feito de forma manual, em que se desenham as metáfases (no mínimo 50 metáfases por paciente), identificando e analisando cada cromossomo, e em seguida as metáfases são impressas e recortadas manualmente (segmentação);

3. Identificação de anomalias - A partir dos cromossomos já identificados, buscase por anomalias que podem ocorrer nos mesmos. Tais anomalias podem estar relacionadas tanto ao número de cromossomos quanto a alterações estruturais. 
Devido ao tempo gasto para se realizar todas estas etapas manualmente, e também devido à quantidade de metáfases que chegam aos laboratórios para serem cariotipadas, surge a necessidade de se automatizar esse processo. Apesar da demanda crescente, ainda é pequena a oferta de sistemas automáticos que auxiliem o trabalho dos geneticistas na coleta de dados e geração do Cariótipo. O processo automático de identificação de cromossomos envolve as seguintes etapas:

1. Etapa de aquisição - da mesma forma que o processo manual, a imagem da metáfase é obtida através de uma câmera acoplada em um microscópio óptico com um aumento de 1000x;

2. Etapa de pré-processamento - Tem como foco principal a preparação da imagem para a etapa de segmentação, tornando possíveis as operações subsequentes, a fim de alcançar um resultado final esperado (ou pelo menos próximo dele). Essa etapa envolve a utilização de diversos filtros tal como suavização, detecção de bordas, realce de contraste, entre outros;

3. Etapa de segmentação - etapa em que se extrai e gera uma nova imagem para cada cromossomo da metáfase. Entre a etapa de segmentação e identificação ainda pode ocorrer uma nova etapa de pré-processamento com a aplicação de novos filtros adequados e que auxiliem o processo de identificação e classificação;

4. Etapa de identificação e classificação - Com as imagens segmentadas e preparadas após a etapa de segmentação, é iniciado o processo de identificação utilizando alguma técnica/algoritmo desenvolvido.

No processo automático de identificação, a etapa de segmentação geralmente envolve algoritmos de detecção de bordas e ajuste de contraste, maneira a delimitar informações referentes ao que representa e ao que não representa um cromossomo na imagem (Figura 2). Já a etapa de identificação dos cromossomos, da mesma forma que o processo manual, envolve a extração de uma série de informações da imagem de forma a auxiliar e tornar possível a realização desta tarefa, tais como o tamanho do cromossomo, a posição do centrômero, o padrão de bandas, entre outras informações [4].

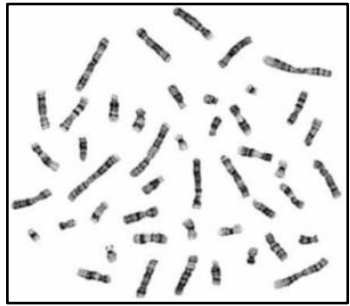

(a)

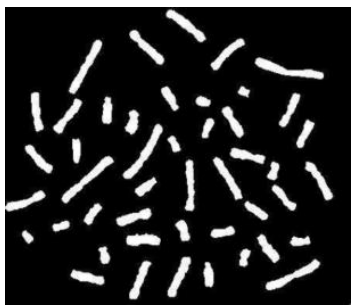

(b)

Figura 2- Exemplo de segmentação (b) de uma metáfase (a), buscando definir o que representa um cromossomo (cor branca) e o que não representa (cor preta). 


\section{Trabalhos Relacionados}

Com relação a trabalhos relacionados, foram realizados estudos sobre dois tipos de trabalhos: primeiramente, estudos relacionados a técnicas e método de processamento de imagens que possibilitem o desenvolvimento de um algoritmo de identificação automática de cromossomos. Em segundo lugar, foram pesquisadas também algumas ferramentas já existentes no mercado que buscam auxiliar o geneticista no processo de elaboração do cariótipo.

\subsection{Ferramentas de auxílio à elaboração do cariótipo}

Com relação à ferramentas existentes, a ferramenta GeneAll [8] utiliza técnicas de deteção de bordas para possibilitar a segmentação da imagem. Além disso, ela ainda permite que o usuário manipule, tanto a imagem original quanto a imagem resultante da segmentação, caso este processo não tenha apresentado um resultado satisfatório. Após a segmentação, a ferramenta apresenta as imagens dos cromossomos classificados, possibilitando que o usuário realize correções, caso o resultado não esteja correto para alguns cromossomos.

Outro produto oferecido no mercado é o software Kario, também desenvolvido com o objetivo de facilitar o trabalho dos geneticistas no reconhecimento do cariótipo [9]. O Kario é um software antigo, e utiliza um banco de dados do Microsoft Access para o armazenamento dos dados textuais, sobre os quais ele permite que sejam feitas consultas.

Ambas as ferramentas apresentadas são softwares comerciais, ou seja, é necessário obetr uma chave para a utilização dos mesmos. Neste trabalho, foi obtida uma chave trial para a realização de testes das mesmas. Observou-se que ambas apresentam problemas, tais interfaces com componentes gráficos antigos e não intuitivas. Os resultados obtidos do processo de segmentação e identificação não são satisfatórios, segundo alguns geneticistas entrevistados, pois ambos os softwares não conseguem realizar a segmentação de cromossomos sobrepostos, pois exigem que o próprio usuário manipule a imagem para a separação dos cromossomos.

\subsection{Técnicas e métodos de identificação de cromossomos}

Diversos trabalhos foram desenvolvidos e publicados buscando investigar a aplicação diferentes técnicas no processo de identificação e classificação de cromossomos humanos. Um estudo detalhado sobre as diferentes técnicas aplicadas na identificação de cromossomos encontradas na literatura é apresentado por [13], que dentre as técnicas mas utilizadas, o autor cita a utilização de modelos estatísticos, redes neurais artificiais, algoritmos de transporte, lógica fuzzy, entre outros. Dentre estes estudos, conforme aponta [13], as técnicas que mais obtiveram sucesso nos resultados são as que envolvem algoritmos estatísticos ou redes neurais artificiais. Na maior parte desses estudos, uma base de dados pública, geralmente de imagens de cromossomos, é utilizada como forma de treinamento para o sistema. 
Em comparação com a técnica desenolvida neste trabalho e apresentada na Seção 4, muitos desses métodos, apesar de apresentarem bons resultados, com taxas de acertos de 70 a $95 \%$, tratam de implemetações com um nível de complexidade elevada. Além disso, muitas bases de dados são antigas, com imagens de baixa qualidade e contendo poucas amostras de cromossomos Este trabalho, que tem como foco o desenvolvimento de uma ferramenta, fez uso de uma técnica mais simples para a identificação, aplicando o cálculo da correlação dos padrões de bandas dos cromossomos sobre os padrões obtidos a partir de uma base de imagens de alta qualidade, a ser apresentado na próxima seção.

\section{$4 \quad$ Metodologia}

O desenvolvimento deste trabalho se dividiu em três etapas: a primeira delas voltada ao desenvolvimento de algoritmos de pré-processamento e segmentação de imagens obtidas a partir de um microscópio, a segunda envolvendo a aplicação de técnicas e métodos com o propósito de realizar a identificação dos cromossomos segmentados, e por fim, o desenvolvimento da ferramenta propriamente dita.

$\mathrm{Na}$ etapa de desenvolvimento de algoritmos de pré-processamento e segmentação, foi utilizada a ferramenta ImageJ [10], que é uma ferramenta para análise e processamento de imagens de código aberto, que fornece bibliotecas que podem ser utilizadas em sistemas externos.

$\mathrm{Na}$ etapa de desenvolvimento de técnicas e métodos de identificação de cromossomos, fez-se uso de uma base de imagens disponibilizada pelo Laboratório de Imagem Biomédica [14], que é constituída imagens de 119 métafases já segmentadas, totalizando 5474 imagens de cromossomos individuais. Essa base foi utilizada para a geração de um perfil médio de cada tipo de cromossomo com base no seu padrão de bandas. Desta forma, a partir de uma nova imagem de entrada já segmentada, são extraídas informações referentes ao padrão de bandas do cromossomo e informações morfológicas sobre o mesmo (comprimento, área, entre outros), e então são aplicadas a um algoritmo de detecção e classificação do cromossomo com relação ao seu centrômero. Em seguida, o padrão de bandas dessas imagens é comparado com o perfil todos os tipos de cromossomos que seguem a mesma classificação com relação ao centrômero, através de um cálculo de correlação, de modo a determinar qual é o cromossomo presente nessa nova imagem.

Para o desenvolvimento da ferramenta, foi escolhida a metodologia ICONIX devido a sua simplicidade e por fornecer uma visão estática (diagramas de domínio e classes) e uma visão dinâmica (diagramas de casos de uso, robustez e sequência) do sistema utilizando a UML (UnifiedModelingLanguage) [5].

Desenvolvida pela ICONIX Software Engineering, o ICONIX se trata de uma metodologia de desenvolvimento de software, com foco em tecnologias orientadas a Objeto, como Java e UML. Destaca-se por ser mais simples que a RUP e mais completa que XP, é conduzida por casos de utilização, interativo e incremental. 
As principais tarefas do ICONIX são:

- Análise de requisitos;

- Análise e desenho preliminar;

- Modelagem;

- Implementação.

No presente artigo serão mostrados os requisitos funcionais e, também, os diagramas de casos de uso e classes.

\subsection{Requisitos Funcionais}

Para a elaboração dos diagramas sugeridos pela metodologia ICONIX, inicialmente foi feito o levantamento dos requisitos do sistema.

- $\quad$ Requisitos Funcionais (RF):

- RF01: Abrir a imagem

- RF02: Efetuar o pré-processamento da imagem

- RF02.1: Suavizar por média

○ RF02.2: Detectar bordas

- RF02.3: Aumentar contraste

○ RF02.4: Efetuar limiarização

- RF02.5: Remover buracos

- RF02.6: Efetuar minimização

- RF04: Definir Região de segmentação da imagem

- RF05: Segmentação dos cromossomos

- RF06: Identificação dos Cromossomos

- RF07: Tratar cromossomos sobrepostos ○ RF07.1: Definir limites de sobreposição

- RF09: Realizar correções do processo de identificação automática.

\subsection{Projeto Do Sistema}

Visando o desenvolvimento de um software com qualidade, foram feitos os diagramas sugeridos pela metodologia ICONIX. Como já fora citado, para o presente artigo, somente serão mostrados os diagramas de casos de uso e classes.

O diagrama de casos de uso, mostrado na Figura 3, mostra a relação entre as funcionalidades do sistema e os atores envolvidos. Nesse caso, somente um tipo de ator, o Usuário do sistema. 


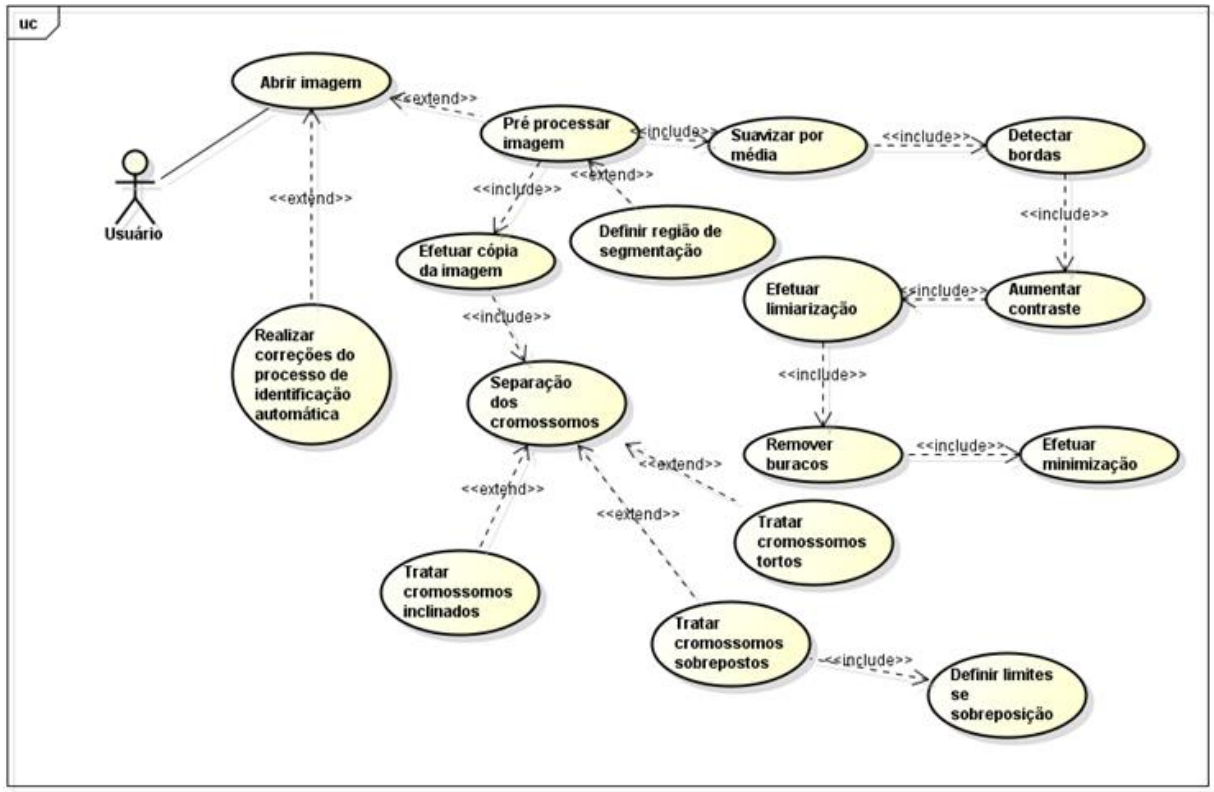

Figura 3 - Diagrama de Casos de Uso.

Os casos de uso que necessitam executar outros casos de uso são representados pela operação de inclusão (Ex.: "Detectar bordas" deve executar o caso de uso "Aumentar contraste" após o término de sua execução). Também há a possibilidade de um caso de uso poder executar (opcional) outro caso de uso após seu encerramento, sendo representado pela operação de extensão (Ex.: "Abrir imagem" pode executar "Pré-processar imagem" após o término de sua execução).

Dentre os diagramas da UML, o diagrama de classes é o mais rico em termos de notação. Ele representa as classes de projeto com seus respectivos atributos e métodos, assim como as relações com outras classes, composições, agregações, heranças, associações, navegabilidade, entre outros [6].

A Figura 4 mostra as classes do sistema e suas associações. Pode-se observar, principalmente, as instâncias da classe "TPonto" pelas classes "TSobrepostos" e "TCromossomos". 


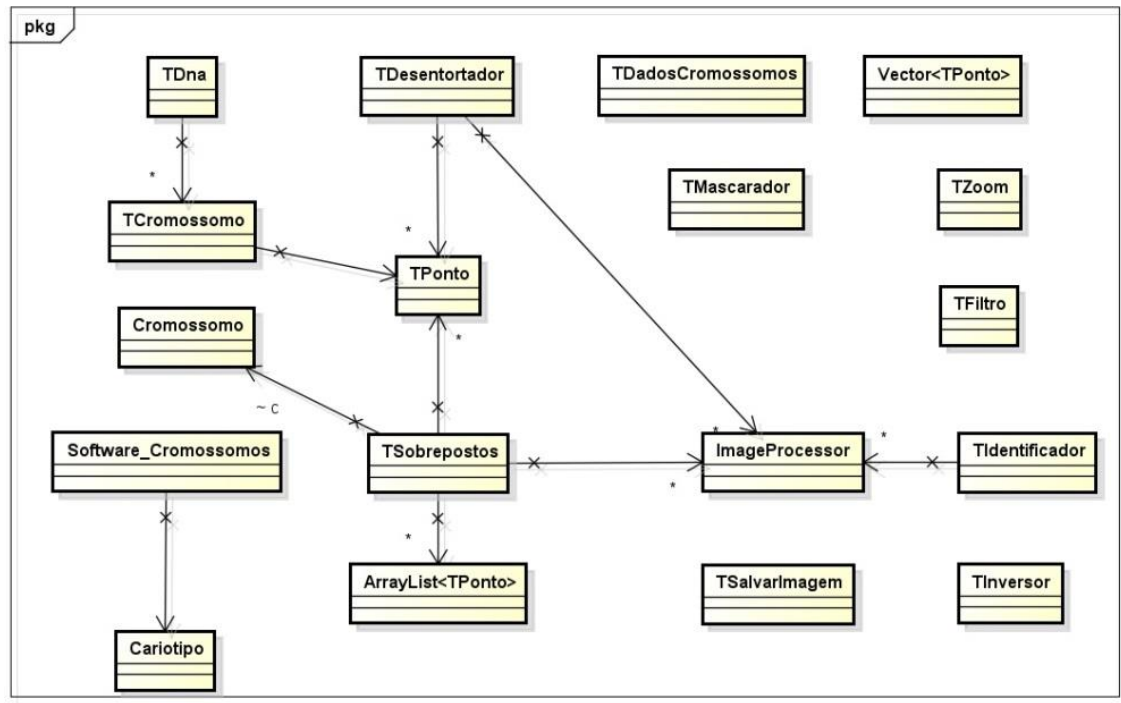

Figura 4- Diagrama de Classes.

\section{Desenvolvimento e e Análise}

Com relação ao desenvolvimento de pré-processamento e segmentação, umas sequência de filtros é aplicada na imagem, todos estes disponibilizados pelas bibliotecas do Imagej: suavização com média de vizinhança 3x3, filtro de detecção de bordas de Sobel, ajuste de constraste, remoção de buracos e fíltro mínimo com vizinhança $3 \times 3$. A seguir a imagem é segmentada através de um algoritmo apresentado anteriormente em [11].

Após a imagem ser segmentada, obtem-se um esqueleto de cada imagem segmentada, que representa o eixo londitudinal que corta o cromossomo no meio, sendo que o algoritmo de esqueletização de imagens utilizado foi o desenvolvido por [15], cuja implementação consta nas bibliotecas do ImageJ [10]. Além disso, são extraídas informações referentes ao padrão de bandas do cromossomo, e também informações morfológicas, tais como seu comprimento, largura, área e perímetro. Essas informações são utilizadas nos algoritmos de detecção e classificação com relação ao centrômero, que foi desenvolvida com base em um perfil da forma do cromossomo denominado shape profile, que leva em consideração tanto o padrão de bandas do cromossomo como também a variação de largura do mesmo no decorrer do seu eixo longitudional (esqueleto), cujo mínimo global é considerado como sendo a posição do centrômero. $\mathrm{O}$ cálculo dos pesos de cada posição do esqueleto e determinação do mínimo global foi feito conforme é apresentado na equação (1), em que gi é o nível de cinza em determinado ponto $i$ e $d i$ é a distância do ponto $i$ para o ponto do esqueleto em questão. Uma descrição mais detalhada sobre o algoritmo de detecção e classificação com relação ao centrômero é apresentada em [12]. 


$$
\text { peso }=\frac{\sum_{i=1}^{n}\left[\left(255-g_{i}\right) *\left(d_{i}\right)^{3}\right]}{\sum_{i=1}^{n} d_{i}}
$$

Na sequência, aplica-se o algoritmo de cálculo do coeficiente de correlação, buscando comparar todas as amostras com os dados obtidos, a partir da base de imagens utilizada, em relação ao padrão de bandas médio de cada tipo de cromossomo. O coeficiente de correlação utilizado é descrito em por (RODGERS e NICEWANDER, 1988). A aplicação destes métodos, tanto de detecção do centrômero quanto de identificação dos cromossomos traz os resultados em poucos segundos. A combinação dessas técnicas possibilitou obter uma taxa de acertos que variam de $80 \%$ a $94 \%$, dependendo da amostra. Em comparação com outros trabalhos relacionados ao tema, acredita-se que, pela simplicidade da técnica de identificação de cromossomos aplicada, esta através do coeficiente de correlação, foram obtidos resultados satisfatórios.

Por fim, desenvolveu-se a ferramenta apresentada neste trabalho, que tem como objetivo auxiliar o processo de cariotipagem realizado por geneticistas buscando acelerar a execução desta tarefa. A tela inicial da ferramenta pode ser vista na Figura 5. Nessa figura, o geneticista tem acesso aos principais menus da aplicação, bem como uma barra de botões que realização ações específicas sobre as imagens, tais como a aplicação de filtros e edição destas, que inicialmente é desabilitada até que o usuário abra uma imagem.

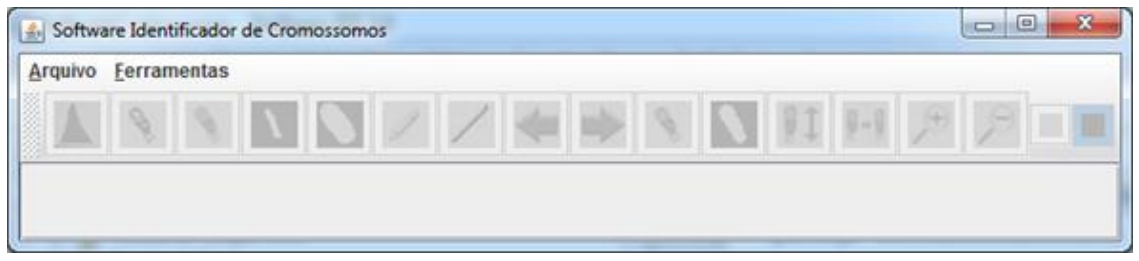

Figura 5- Tela inicial da ferramenta.

Ao abrir a imagem de uma metáfase através do menu Arquivo - Abrir, os botões da barra de botões são habilitados, possibilitando editar a imagem e aplicar filtros na mesma caso seja necessário, conforme mostra a Figura 6. Os filtros encontrados na ferramenta são de suavização da imagem, intensificação, dilatação, erosão, bem como um ajuste de contraste. Estes filtros são importantes, pois possibilita que o geneticista melhore a qualidade de uma imagem obtida através do microscópio. 


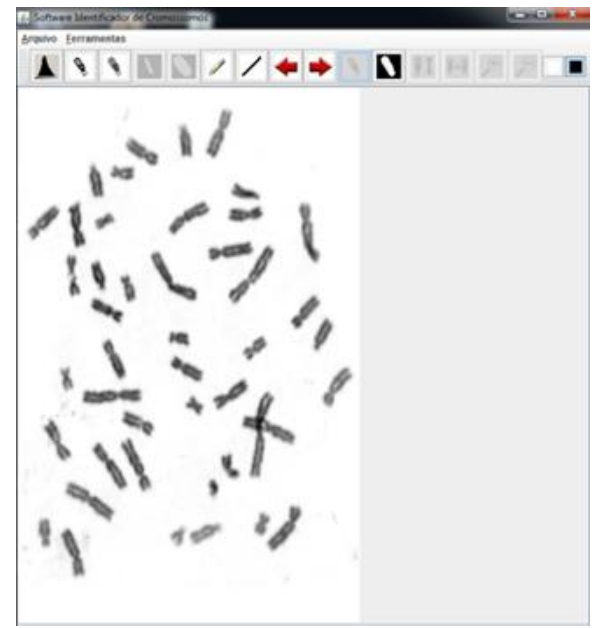

Figura 6- Tela da ferramenta após abrir uma imagem de uma metáfase.

Além disso, o usuário também tem acesso a uma imagem auxiliar denominada máscara, que serve como referência para o software determinar o que é (cor branca) e o que não um cromossomo (cor preta) na imagem (Figura 7). $\mathrm{O}$ usuário tem a possibilidade de editar qualquer uma dessas imagens, buscando auxiliar no processo de identificação através de uma melhor delimitação dos cromossomos.

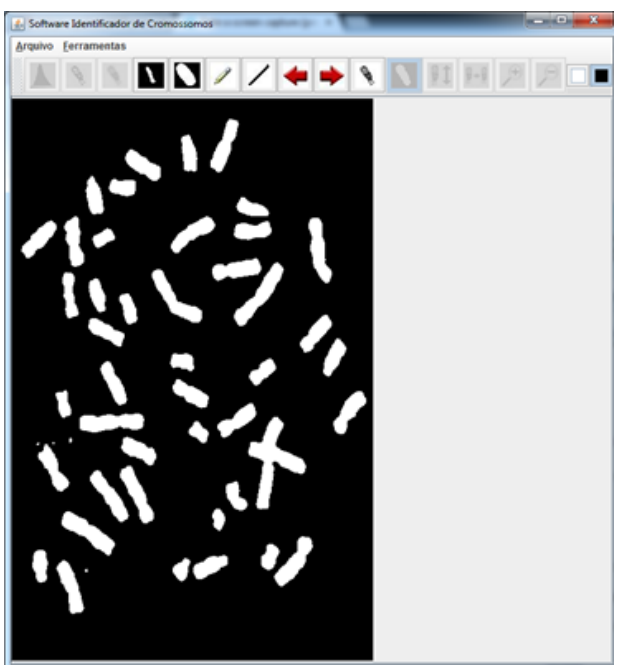

Figura 7- Tela da ferramenta apresentando a máscara da imagem original. 
O processo de segmentação e identificação dos cromossomos inicia-se a partir do momento que o usuário escolhe a opção Identificar no menu Ferramentas.

Apesar do processo de identificação ser automático, exista a possibilidade de que alguns cromossomos sobrepostos sejam encontrados em uma imagem. A verificação da sobreposição é feita com base no esqueleto da imagem, que apresentará mais de dos limites, conforme apresentado em [11]. No momento em que isso acontece, uma janela é aberta para o usuário auxiliar o sistema a identificar e delimitar quais são os eixos longitudinais dos cromossomos que estão sobrepostos, conforme mostra a Figura 8. Isso acontece para todos os casos de cromossomos que estejam sobrepostos ou encostados uns aos outros, pois assim é possível obter resultados mais satisfatórios na segmentação.

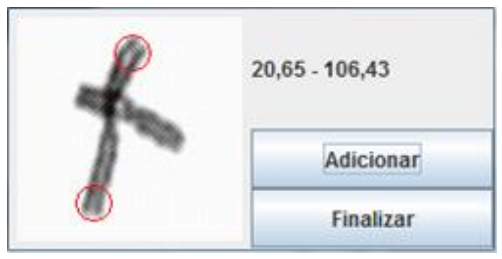

Figura 8- Janela responsável por lidar com a separação de cromossomos sobrepostos através de interação com o usuário.

Ao final do processo de identificação, é apresentado ao usuário o resultado da mesma, conforme mostra a Figura 9.a. Nesta tela, os cromossomos, já segmentados e identificados, são dispostos em imagens independentes. Aqui, o usuário é capaz de corrigir possíveis erros na identificação, bem como trocar imagens de lugar umas com as outras e inverter verticalmente uma imagem. Ao finalizar as correções, o usuário pode finalmente gerar o cariótipo através do menu Arquivo - Salvar Cariótipo. O resultado é uma imagem semelhante ao demonstrado na Figura 9.b.

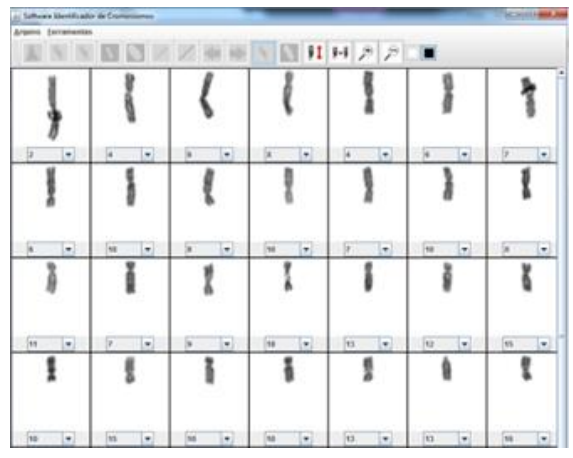

(a)

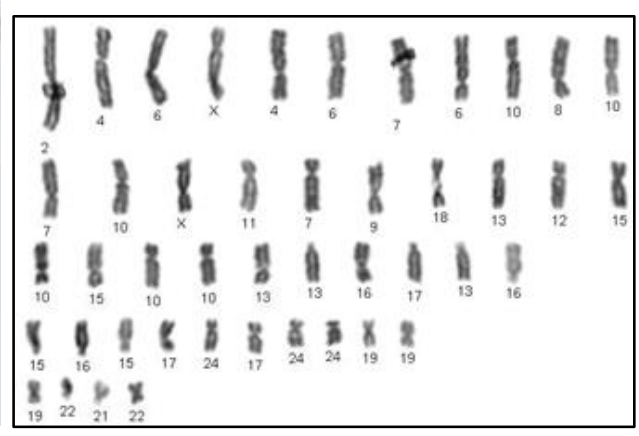

(b)

Figura 9- Resultado do processo de segmentação e identificação dos cromossomos (a) e cariótipo da imagem salvo pelo usuário (b). 


\section{Conclusão}

Este trabalho teve como principal objetivo o desenvolvimento de um software para auxilio no processo de elaboração do cariótipo por parte dos geneticistas, através de imagens obtidas a partir de um microscópio. A ferramenta faz uso de técnicas de processamento de imagens e reconhecimento de padrões de forma a automatizar esse processo. Com o intuito de ser uma ferramenta de auxilio, os resultados obtidos no processo de segmentação e identificação dos cromossomos não são perfeitos, logo, é importante ressaltar que esta ferramenta tem como foco auxiliar o geneticista, ou seja, oferecer-lhe uma ferramenta com funcionalidades que facilitem o seu trabalho de elaboração do cariótipo.

Apesar da grande demanda de profissionais capacitados da área de Genética Médica para a execução do cariótipo, o número de profissionais qualificados ainda é baixo. A Citogenética surgiu com o intuito de pesquisar alterações que ocorrem em nível de DNA nas populações e estudar agentes mutagênicos, sendo que uma das técnicas mais utilizadas para a realização deste trabalho é a análise do cariótipo. Desta forma, a análise do cariótipo é de suma importância para o diagnóstico de doenças ligadas a alterações cromossomicas, e, portanto, a automatização deste processo é essencial, visando obter resultados mais confiáveis e em um espaço de tempo menor, apesar de que ainda é baixa a oferta de sistemas deste tipo.

Em relação a trabalhos futuros, pretende-se adicionar novas funcionalidades a ferramenta, tais como filtros e outras possibilidades de edição de imagens. Além disso, pretende-se ainda realizar a adição de um módulo para a elaboração de laudos, estes a partir dos resultados obtidos através da análise do cariótipo, que também é de grande importância.

\section{Referências}

[1] BRUNONI, D. Estado atual do desenvolvimento dos serviços de genética médica no Brasil. Revista Brasileira de Genética, v. 20 (Suppl. 1), p.11-23, 1997.

[2] BRUNONI, D. Aconselhamento genético. Ciência \& Saúde Coletiva, v. 7, p. 101 107, n. 1, 2002.

[3] NUSSBAUM, R.L.; MCINNES, R.R.; WILLARD, H.F. Thompson e Thompson: Genética Médica. $7^{\mathrm{a}}$ ed., Elsevier Editora Ltda - Rio de Janeiro, 2008.

[4] MORADI, M.; SETAREHDAN, S.K. New features for automatic classification of human chromosomes: A feasibility study. Pattern Recognition Letters, v. 27, p. 19-28, n. 1, 2006.

[5] ROSENBERG, D.; STEPHENS, M. Use Case Driven Object Modeling with UML: Theory and Practice. United StatesofAmerica: Apress, 2007. 
[6] BEZERRA, E. Princípios de Análise e Projeto de Sistemas com UML. 2a ed., Elsevier Editora Ltda - Rio de Janeiro, 2006.

[7] CAPUTO, Z.C. Chromos: Laboratório de Citogenética. Disponível em: <http://www.chromoscitogenetica.com.br/>. Acesso em 04 de ago. 2015.

[8] GENEALL, Q: Editor de Cariótipos Profissional. Disponível em < http://www.qualiterm.com.br/geneall_cariotipos.htm> Acesso em ago. 2015.

[9] IMAGING, Z. Kario. Disponível em: <http://imageanalysis.altervista.org>. Acesso acesso em ago. 2015.

[10] RASBAND, W. S. ImageJ. U. S. National Institutes of Health, Bethesda, Maryland, USA, Disponível em <http://ImageJ.nih.gov/ij/>, 2011.

[11] KURTZ, G. C.; BONINI, T.; PERLES, L. A.; SAGRILLO, M. R.; LIBRELOTTO, G. R. Identificação automática de cromossomos humanos. SIBGRAPI 2008 - XXI Brazilian Symposium on Computer Graphics and Image Processing, Campo Grande p. 33-36, 2008.

[12] KURTZ, G. C.; PERleS, L. A.; SAGRIllo, M. R.; LiBrelotTO, G. R. Processamento de Imagens aplicado ao Reconhecimento do Cariótipo e ao Processo de Detecção do Centrômero. CreateSpace Independent Publishing Platform, 2013.

[13] WANG, X.; ZHENG, B.; LI, S.; MUlVIHILL, J. J.; WOOD, M. C.; LIU, H. Automated classification of metaphase chromosomes: optimization of an adaptive computerized scheme. Journal of biomedical informatics, v. 42, p 22-31, 2009.

[14] POLETTI, E.; GRISAN, E.; RUGGERI, A. Automatic classification of chromosomes in Qband images. 30th Annual International Conference of the IEEE-EMBS, Vancouver, British Columbia, Canada, p. 20-24, 2008.

[15] ZHANG, T. Y.; SUEN, C. Y. A fast parallel algorithm for thinning digital patterns. Commun. ACM, v. 27, n. 3, p. 236-239, 1984.

[16] NATARAJAN, A.T., PALITTI, F. DNA repair and chromosome alterations. Mutation Reserch, Nov.17; 657(1): p.3-7, 2008.

[17] MATEUCA, R., LOMBAERT, N., AKA, P.V., DECORDIER, I., KIRSCHVOLDERS, M. Chromosomal changes: induction, detection methods and applicability in human biomonitoring. Biochimie. Nov;88(11):1515-31. Epub 2006 Aug 4, 2006. 